\title{
La lucha antituberculosa en la primera década de la salud pública revolucionaria
}

\section{The anti-tuberculosis struggle during the first decade of the revolutionary public health period}

\author{
DrC. Enrique Beldarraín Chaple \\ Centro Nacional de Información de Ciencias Médicas-Infomed. La Habana, Cuba.
}

\begin{abstract}
RESUMEN
Se estudió la lucha contra la tuberculosis en Cuba en la década de 1959-1969, cuando se organizó por primera vez un programa para su enfrentamiento, se analizan las diversas modificaciones que se hicieron, las principales actividades para conocer la magnitud del problema y los primeros resultados de la aplicación del programa. Asimismo, se hace referencia a las personas que trabajaron, diseñaron e impulsaron las actividades necesarias y que a su vez formaron a las siguientes generaciones en el control de la tuberculosis en Cuba.
\end{abstract}

Palabras clave: Tuberculosis, Cuba, historia, lucha antituberculosa.

\begin{abstract}
This paper presented the study of the anti-tuberculosis struggle in Cuba in the 1959-1969 period, when a program to face this disease was organized for the first time; the various changes made, the main activities to find out the scope of the problem and the first results of the implementation of this program were also analyzed. Likewise, reference was made to those people who worked, designed and encouraged the necessary activities to attain this goal and who were in charge of the formation of the subsequent generations for the control of tuberculosis in Cuba.
\end{abstract}

Key words: Tuberculosis, Cuba, history, anti-tuberculosis fight. 


\section{INTRODUCCIÓN}

Actualmente se hace un gran esfuerzo mundial para controlar la tuberculosis (TB) en una escala global. ${ }^{1}$ La región de Las Américas aborda fuertemente ese plan, priorizando los países de alta carga como Brasil y Bolivia. ${ }^{2}$ Por otra parte, estimula a los países latinoamericanos con baja incidencia de TB para avanzar hacia su eliminación como problema de salud pública. ${ }^{3}$ Cuba muestra una de las situaciones más favorables concerniente a la TB en Las Américas, ${ }^{4}$ muy próxima a la de Canadá y EE. UU. ${ }^{5}$ Los resultados que se cosechan hoy en ese sentido, constituyen la expresión concreta a mediano y largo plazo, de las políticas, estrategias y tácticas desarrolladas por los dirigentes políticos, administradores, dirigentes del sector de la salud y los especialistas profesionales-técnicos cubanos y los asesores foráneos de países amigos que trabajaron y colaboraron entre los años 1959 y 1969 . Es importante que la nueva generación del tercer milenio conozca mejor las condiciones y características de esas políticas, estrategias y acciones de control, que ciertamente se tornaron avanzadas para su época. Este trabajo tiene por objetivo describir y sistematizar las principales experiencias históricas del control de la tuberculosis en la década estudiada, con mención incluida de un conjunto de sus actores.

\section{MÉTODOS}

Se aplicaron técnicas cualitativas consistentes en revisiones documentales y conversaciones-entrevistas abiertas con informadores claves. Se revisó la información contenida en los Programas de Control de la Tuberculosis, diseñados e implementados por el Ministerio de Salud Pública (MINSAP) desde el primero (1963), hasta el último al final del período estudiado, así como sus adecuaciones y evaluaciones. Dichos documentos se encuentran en al archivo personal del profesor doctor Edilberto González Ochoa y de la Licenciada Dalia Fernández Vila, quiénes trabajaron durante la década de estudio en la Dirección Nacional del Programa de Control de la TB. También se revisó la documentación publicada de la primera reunión nacional de Directores Hospitales y Dispensarios Antituberculosos y Jefes de Servicios de Tisiología celebrada en La Habana, noviembre de 1961, así como lo relativo a la enfermedad discutido en el Primer Forum Nacional de Higiene y Epidemiología efectuado en La Habana en 1962, organizado por el MINSAP. Además se revisó un conjunto de artículos científicos publicados en las memorias de estos dos eventos, en las Revistas o Boletines Médicos Nacionales y otros informes técnicos y gerenciales (resoluciones).

Se obtuvieron datos de la época del estudio mediante varias conversacionesentrevistas con la licenciada Dalia Fernández Vila, durante los meses de junio-agosto de 2008. Además, se realizó una entrevista por parte de la Licenciada Fernández Vila y el autor a la doctora Alicia Casanovas, tisiopediatra, quien trabajó primero en este servicio en Santiago de Cuba y posteriormente en la Dirección Nacional del Programa. También el autor entrevistó al profesor doctor Helenio Ferrer Gracia, quién dirigió el Departamento Nacional de Epidemiología del MINSAP durante la década del 1960. 
Contamos además con los aportes de las conversaciones-entrevistas del profesor Edilberto González Ochoa, quién trabajó como Epidemiólogo de la Dirección Nacional del Programa de TB a partir del año 1967.

Se utilizaron importantes opiniones e informes publicados por el doctor Gustavo Aldereguía Lima, quién fue desde el inicio de 1959 Director del Departamento de Tuberculosis y Jefe de su Programa Nacional de Control posteriormente, hasta su fallecimiento (1970).

Se utilizaron además informaciones del autor obtenidas para una investigación anterior y en partes publicadas como artículos en diversas revistas, así como estadísticas oficiales del MINSAP.

\section{Antecedentes de la formulación del Programa de Lucha Antituberculosa}

En los primeros meses de 1959 se efectuaron importantes y sustanciales cambios en el antiguo Ministerio de Salubridad y Asistencia Social, posteriormente surgió el MINSAP y uno de sus principales cambios fue en las políticas y estrategias de sus esfuerzos de trabajo, que comenzaron a dirigirse hacia la prevención de enfermedades, junto con el crecimiento de los servicios médicos, su extensión a todo el país paulatinamente, (según lo permitieran las condiciones concretas) y la asistencia médica gratuita a toda la población necesitada. En esa etapa se infería que el problema de la TB en Cuba era grave, pero la información disponible, limitada y poco confiable, no permitía elaborar un cuadro de la verdadera magnitud de la situación.

En 1961 se realizó el primer análisis de la situación de la tuberculosis expuesto por los doctores Aldereguía Lima y Luis Pascual Gispert. ${ }^{6-8}$ En esos momentos se reconoció la gran importancia de las personas excretoras de bacilos como índice epidemiológico, así como el de los niños reactores a la prueba tuberculínica.

Fue necesario emplear como indicador la frecuencia de imágenes radiográficas significativas, lo que ya al final de la década del 1960 no se tomaba en cuenta como indicador epidemiológico.

Se usaron entonces los índices de prevalencia de infección y tasas de mortalidad e incidencias para tener una idea de la magnitud del problema. Se reconocía desde mucho tiempo antes que la prevalencia de la infección es el parámetro más importante para demostrar el grado de exposición al bacilo. En 1961 se estimó una tasa de prevalencia de la tuberculosis activa bacilífera de 0,7\%. Hasta ese momento no se habían ejecutado encuestas adecuadas para determinar la prevalencia en el país. ${ }^{8-10}$

Cuando se organizaron los registros de los pacientes inscritos y tratados en los 25 dispensarios del país y se estableció el Sistema de Notificación de Enfermedades de Declaración Obligatoria, que incluía a la tuberculosis, se pudieron establecer cifras del número de enfermos que estaban activos en ese momento, en todo el territorio nacional.

En 1964 se inició una intensa búsqueda de casos a través del examen fotorradiográfico que logró en 1965 sobrepasar el número de un millón de exámenes. Ese año se reportó una tasa de prevalencia de $0,3 \%$ dada por los casos 
conocidos de la enfermedad. Se incluían los casos registrados y se admitieron también los que no tenían confirmación bacteriológica.

Esta fue la situación con la que se enfrentaron los especialistas del MINSAP, que desde el Departamento de Tuberculosis y de la Dirección de Epidemiología, diseñaron y aplicaron el primer Programa de Control contra la Tuberculosis, a finales de 1963.

En 1959 tras el triunfo de la Revolución se reestructuró el antiguo Ministerio de Salubridad y Asistencia Social, llamándose Ministerio de Salubridad y Asistencia Hospitalaria, en 1960 cambió su nombre a Ministerio de Salud Pública y una de las tareas iniciales fue organizar la lucha contra la TB, enfermedad de origen social que afectaba profundamente a la población. En Cuba, al frente de estas tareas se nombró a un especialista muy ligado a la enfermedad y a la lucha social, desde las primeras décadas del siglo xx: el doctor Gustavo Aldereguía Lima, como director del Departamento de Tisiología y su Comisión Nacional, dentro de la subsecretaria de Asistencia Médica.

Cuando este departamento inició sus trabajos, no se había realizado ningún estudio verdaderamente serio, de carácter epidemiológico, para conocer la magnitud de la TB en Cuba, ni existían datos estadísticos fidedignos. No se realizaba educación sanitaria; la vacunación BCG si bien ya era de uso desde décadas anteriores, se practicaba en cifras insignificantes en relación con el número de población a proteger, ya que las dosis aplicadas en todo el territorio nacional ascendía a un promedio anual de 10000 y el examen fotorradiográfico en masa de la población para el diagnóstico de tuberculosis en personas supuestamente sanas, se hacía de forma superficial y en 18 meses de labor solo se habían realizado $9700 .^{6-8}$

La vacunación BCG, se comenzó a aplicar de forma más organizada y general, entre el 1 de enero de 1959 hasta el 30 de junio de 1961. Se logró aplicar un total de 808 475, dosis en todo el territorio nacional, lo que significó una elevación importante del nivel inmunitario de los recién nacidos, dirigido a la disminución del riesgo de enfermar con formas graves en la población infantojuvenil.

La pesquisa fotorradiográfica, rediseñada su estrategia de trabajo, alcanzó 180463 exámenes en 1959, y se inició una búsqueda en masa en el seno del Ejército Rebelde, conocido como "Operación Celia Sánchez", que fue la primera de su estilo. Todos los enfermos identificados fueron atendidos con preferencia. El doctor Pedro Baeza, quién en esos momentos era el director del Sanatorio de Cangrejeras, cerca de Bauta, fue el encargado del tratamiento. Se les dio alojamiento adecuado y atención médica en un pabellón especial y aislado, que se llamó "Mario Muñoz". ${ }^{6}$ Entre las 180463 personas pesquisadas en el año 1959, se descubrieron 1877 casos de tuberculosis, lo que arrojó una prevalencia de 1,0 \%. En 1960 la pesquisa aumentó hasta 224735 personas examinadas, encontrándose 1732 enfermos, (0,8 \%). En el primer semestre de 1961 la indagación fotorradiográfica cubrió a 11364 personas, descubriéndose 456 enfermos.

En este último período se realizaron las operaciones "Varadero" y "Ciénaga de Zapata". Estas operaciones fueron un verdadero ejercicio de terreno para el diagnóstico de la enfermedad e inicio de su tratamiento, lo que representó un impulso muy importante a la lucha antituberculosa, que tomaba la estrategia de campañas, lo que coincidía con el pensamiento epidemiológico de la dirección del MINSAP, que había decidido arremeter contra un grupo de enfermedades infectocontagiosas que constituían verdaderos problemas de salud pública. 
La "Operación Varadero" constituyó un muestrario nacional porque cubrió a la casi totalidad de los brigadistas alfabetizadores que pasaron por allí. Fue planeada y dirigida por el Departamento de Tuberculosis, como vía de atención a los brigadistas, después de haber terminado sus tareas de alfabetización en los diferentes lugares del país. Mediante la fotorradiografía se examinaron 84131 alfabetizadores, además del personal auxiliar, especialmente cocineros y sirvientes. Todos los enfermos descubiertos y confirmados fueron hospitalizados en sanatorios, o en las salas de las Casas de Salud de los Centros Regionales (clínicas mutualistas). Los enfermos evolucionaron hacia la curación casi todos, por lo inicial de las lesiones y la oportunidad del diagnóstico, la mayoría recibió el tratamiento ambulatorio prolongado. ${ }^{6}$

La "Operación Ciénaga de Zapata" tuvo otras características, cubrió a la población del territorio de la Ciénaga, desde siempre aislada, con muy malas condiciones de vida, extrema pobreza, caracterizada por la desnutrición, el hambre trófica; las enfermedades infectocontagiosas, parasitarias, carenciales y orgánicas, presentes en gran parte de su población y sobre todo en la infantil. A pesar de que desde 1959 se había comenzado un proceso de transformaciones en la composición política, social, económica, cultural, sanitaria y epidemiológica del territorio, la tuberculosis, como enfermedad crónica, estaba presente presumiblemente con altas cifras de prevalencia.

Terminada la "Operación Varadero", pasaron las unidades móviles de fotorradiografía a la Península de Zapata, para iniciar una ofensiva de salud pública, pesquisa de tuberculosis y otras enfermedades torácicas y una campaña de vacunación masiva a sus pobladores, estas tareas la acometieron conjuntamente el Departamento de Tuberculosis y el de Epidemiología del MINSAP. Se realizaron un total de 10272 exámenes fotorradiográficos, entre los que se descubrieron 97 casos (66 hombres y 31 mujeres, de ellos 54 campesinos y 43 de poblaciones urbanas) con un índice de $0,9 .{ }^{6}$ Se aplicaron más de 30000 dosis de vacunas BCG en esta campaña. En estas tareas además de los compañeros del nivel central del MINSAP, se destacaron de forma meritoria una compañera del servicio social, Gladys Esquirol, y Abraham Maciques, quién era el jefe militar de la zona y que prestó en todo momento su apoyo y colaboración.

\section{Situación de la tuberculosis en Cuba}

Con el grado de organización que tenía la Dirección de Epidemiología del MINSAP y del Departamento de Tuberculosis, se imponía ya el diseño y puesta en marcha de un programa de control.

Previo al diseño de un programa, la Organización Mundial de la Salud (OMS) recomienda realizar una Encuesta de Prevalencia, efectuada sobre muestras representativa de población seleccionadas al azar, en la región donde funcionará el programa.

En Cuba solo existía un estudio previo sobre la situación de la TB a escala nacional, realizado por los doctores $R$. Ballesteros y J.M. Hernández, ${ }^{11}$ en 1952. En dicho estudio examinaron 70958 personas, a las que le realizaron pruebas de tuberculina intradérmica utilizando el Antígeno Tuberculinico Bacilar (A.T.B.) y como criterio de positivos las infiltraciones mayores de $5 \mathrm{~mm}$. Fue el más amplio de los estudios sobre la frecuencia de la infección en Cuba. ${ }^{11}$ De este estudio se concluyó que la frecuencia de la infección tuberculosa era muy alta, ya que al año de edad, el $24 \%$ de los niños estaban infectados; a los 5 años, los reactores llegaban al $40 \%$, a los 
15 casi al $60 \%$. Estas eran cifras muy altas. En la época que se realizó, no se conocía en Cuba el patrón de sensibilidad tuberculínica, por lo que es posible que muchos casos positivos pudieran tratarse de reacciones inespecíficas.

Del trabajo de los doctores Ballesteros y Hernández, podemos obtener los datos que se muestran en las tablas 1,2 y 3.

Tabla 1. Frecuencia de la infección tuberculosa según prueba de tuberculina y grupos de edades (1952)

\begin{tabular}{|l|c|}
\hline $\begin{array}{l}\text { Grupos } \\
\text { de edades (años) }\end{array}$ & $\begin{array}{c}\text { \% de reactores } \\
\text { positivos }\end{array}$ \\
\hline Menores de 1 & 24,0 \\
\hline $1-2$ & 31,2 \\
\hline $2-3$ & 35,7 \\
\hline $3-5$ & 40,1 \\
\hline $5-10$ & 48,5 \\
\hline $10-15$ & 59,0 \\
\hline $15-20$ & 76,1 \\
\hline Mayores de 20 & 92,3 \\
\hline
\end{tabular}

Fuente: Ob. cit.11.

Tabla 2. Frecuencia de la infección tuberculosa según prueba de tuberculina intradérmica por provincias y grupos de edades (1952)

\begin{tabular}{|c|c|c|c|c|c|c|}
\hline $\begin{array}{l}\text { Grupos } \\
\text { de edades } \\
\text { (años) }\end{array}$ & $\begin{array}{l}\text { Pinar } \\
\text { del Río }\end{array}$ & $\begin{array}{c}\text { La } \\
\text { Habana }\end{array}$ & Matanzas & $\begin{array}{l}\text { Las } \\
\text { Villas }\end{array}$ & Camagüey & Oriente \\
\hline $1-5$ & 28,2 & 42,1 & 22,5 & 43,9 & 30,4 & 47,5 \\
\hline $5-10$ & 53,3 & 49,6 & 45,2 & 45,2 & 35,8 & 57,3 \\
\hline $10-15$ & 48,9 & 59,1 & 53,9 & 57,8 & 54,0 & 67,4 \\
\hline
\end{tabular}

Fuente: ob. cit.11. 
Tabla 3. Frecuencia de la infección tuberculosa según prueba de tuberculina intradérmica, por provincias y grupos de edades y su interrelación con características generales, sociales, culturales y económicas

\begin{tabular}{|c|c|c|c|c|c|c|c|c|}
\hline \multicolumn{3}{|c|}{$\begin{array}{l}\% \text { de reactores } \\
\text { positivos (años) }\end{array}$} & \multirow{2}{*}{ Provincias } & \multirow{2}{*}{$\begin{array}{c}\text { Densidad } \\
\text { (habitantes } \\
\times \mathrm{km}^{2} \text { ) }\end{array}$} & \multirow{2}{*}{$\begin{array}{c}\% \\
\text { población } \\
\text { urbana } \\
\text { (a) }\end{array}$} & \multirow{2}{*}{$\begin{array}{l}\text { Promedio } \\
\text { personas } \\
\text { por familia }\end{array}$} & \multirow{2}{*}{$\begin{array}{c}\% \\
\text { de } \\
\text { analfabetos } \\
\text { (b) }\end{array}$} & \multirow{2}{*}{$\begin{array}{c}\% \\
\text { de } \\
\text { fuerza } \\
\text { de } \\
\text { trabajo } \\
\text { (c) }\end{array}$} \\
\hline $3-5$ & $5-10$ & $10-15$ & & & & & & \\
\hline 47,5 & 57,3 & 67,4 & Oriente & 49,1 & 39,8 & 5,7 & 35,3 & 52,8 \\
\hline 42,1 & 49,6 & 59,1 & La Habana & 187,2 & 91,4 & 4,0 & 9,2 & 53,5 \\
\hline 43,2 & 45,1 & 57,8 & Las villas & 48,1 & 49,7 & 5,1 & 24,9 & 52,5 \\
\hline 30,4 & 35,8 & 54,0 & Camagüey & 23,5 & 49,7 & 4,9 & 27,3 & 55,5 \\
\hline 22,5 & 45,2 & 53,9 & Matanzas & 46,9 & 58,6 & 4,7 & 19,2 & 50,7 \\
\hline 28,2 & 35,3 & 48,9 & P. del Río & 33,1 & 34,1 & 5,4 & 30,8 & 62,5 \\
\hline
\end{tabular}

Fuente: Ob. cit.11.

Según estos estudios la situación de la enfermedad era preocupante, en todos los grupos de edades y justificaba la creación de un programa de lucha contra la enfermedad, pero en el momento de su realización aunque existían instituciones cuyo objetivo era este, no existía la voluntad política en dichas instituciones, ni fuera de ellas para llevarlo a cabo. En el resto de la década de 1950 la situación continuó en incremento, aunque entre los años 1953 y 1959 la mortalidad disminuyó muy ligeramente, como se puede apreciar en la tabla 4 y disminuyó aún más en el año 1960 (tabla 5 y 6). En estas fechas ya se contaban con tratamientos más efectivos, con antibióticos específicos, tratamientos quirúrgicos y otros, que alargaban la vida de los pacientes.

Tabla 4. Lugar que ocupa la tuberculosis del sistema respiratorio entre las diez primeras causas de muerte en los años señalados

\begin{tabular}{|l|c|c|c|}
\hline Años & $\begin{array}{c}\text { No. } \\
\text { de defunciones }\end{array}$ & $\begin{array}{c}\text { Tasa } \\
\text { por } \\
000 \text { hab. }\end{array}$ & Lugar \\
\hline 1953 & 1128 & 19,2 & $8 \mathrm{vo}$ \\
\hline 1955 & 1097 & 17,9 & 9 no. \\
\hline 1957 & 1114 & 17,4 & $10 \mathrm{mo}$. \\
\hline 1959 & 1095 & 16,4 & $10 \mathrm{mo}$. \\
\hline
\end{tabular}


Tabla 5. Defunciones totales y por tuberculosis registradas durante los años 1958-1960

\begin{tabular}{|c|c|c|c|c|c|c|}
\hline \multirow{2}{*}{ Conceptos } & \multicolumn{2}{|c|}{1958} & \multicolumn{2}{|c|}{1959} & \multicolumn{2}{|c|}{1960} \\
\hline & No. & Tasa & No. & Tasa & No. & Tasa \\
\hline Mortalidad global & 41959 & 6,4 & 43423 & 6,5 & 42244 & 6,2 \\
\hline Mortalidad, todas las formas de TB & 1076 & 16,5 & 1146 & 17,2 & 1053 & 15,4 \\
\hline Sistema respiratorio & 1018 & 15,6 & 1095 & 16,4 & 1014 & 14,9 \\
\hline
\end{tabular}

Fuente: Departamento de Estadísticas del MINSAP.

Tabla 6. Tasa de mortalidad por tuberculosis del sistema respiratorio 1953 y 1959

\begin{tabular}{|l|c|c|c|}
\hline \multicolumn{1}{|l|}{} & Total & Varones & Hembras \\
\cline { 2 - 4 } & & & \\
\hline 1953 & Tasa & Tasa & Tasa \\
\hline 1959 & 19,3 & 22,2 & 16,3 \\
\hline 19,4 & 19,2 & 13,5 \\
\hline
\end{tabular}

Fuente: ob cit.8.

Estimulado por la falta de estudios y la necesidad de conocer la realidad con la cual iban a trabajar, el doctor Luís Pascual Gispert, especialista del Departamento Nacional de Tuberculosis, decidió en 1960 realizar un estudio para estimar la situación de la enfermedad, el mismo incluyó a 216218 personas. $^{8}$

Esta investigación seleccionó del total de casos examinados por el Dispensario Regional de Tuberculosis de La Habana, mediante pesquisas fotorradiográficas, en 1960, una muestra de 216218 habitantes, mayores de 15 años. Esta muestra estaba integrada por distintos estratos de nuestro universo, comprendió a personas de ambos sexos, de todos los grupos étnicos y de edades, residentes de zonas urbanas y rurales, de distintos estados civiles y profesionales, incluyó además población penal y hospitalaria, ingresada por trastornos mentales. Se obtuvo por muestreo estratificado y pretendió representar la prevalencia de la tuberculosis en la población mayor de 15 años en ese momento. La prevalencia total de la muestra fue de $1,0 \%$, en la población urbana fue de 1,02 y la rural de 0,52. En el sexo masculino fue de $1,11 \%$ y en el femenino de $0,67 \%$. Las personas comprendidas en el grupo étnico clasificado como blancos fueron las más afectadas con 0,91, los comprendidos entre los negros 0,89 y los mestizos 0,75 . Los descendientes de "asiáticos" (amarillos) tuvieron la más alta prevalencia que alcanzó casi el $4 \%$ (se calculó que existían en el país en esos momentos unos 30000 "asiáticos"). Las edades más afectadas fueron los mayores de 39 años, la prevalencia más alta se obtuvo entre los 60 y 69 años, con 5,59. La frecuencia de TB pulmonar mínima fue de $72 \%$, la moderadamente avanzada $18 \%$, y la avanzada 4,3\%.

Las otras tuberculosis (primo infecciones, pleural y deformaciones por tratamientotoracoplastias y resecciones-), el 6,1\%.

http://scielo.sld.cu 
En relación con el estudio de la actividad microbiana, la búsqueda del bacilo no se efectuó en todos los casos, el total no sobrepasó el 30 \%. Los casos activos el 57 \% y los inactivos, $43 \%$.

Como la prevalencia del estudio fue de $1,0 \%$ se pudo calcular para 1962, para todo el país una cifra de 45000 tuberculosos para mayores de 15 años (población mayor 15 años estimada era de 4504 193, a 30 de junio 1962) y de estos 25000 serían casos activos.

En 1961, el Doctor Luís Pascual Gispert realizó un examen a 36130 escolares comprendidos entre 10 y 14 años, encontró la tuberculosis en $16(0,04 \%$ de prevalencia). La población cubana menor de 15 años, estaba constituida en esa fecha por 2518157 habitantes, en el supuesto de que fuera cuatro veces más alta para las edades de 0-14 años, no pasarían de 4 100, lo que sumado al número de los mayores de 15, no llegaría a la cifra de 55000 casos en todas las edades. ${ }^{8}$

Aunque el estudio tuvo sus limitaciones, sirvió para tener una idea de la situación de la enfermedad a los inicios de la década de 1960 y también fue uno de los insumos necesarios para la planificación del Programa de Control de la Tuberculosis, que se iniciaría en 1963.

\section{La pesquisa fotorradiográfica}

El Departamento de Tuberculosis con el doctor Aldereguía Lima a la cabeza, decidió entre sus primeras acciones, utilizar la técnica de la fotorradiografía (FR) para hacer un pesquisaje a gran escala de la población cubana en busca de posibles enfermos de TB.

Para ello contó con la técnica radiológica, que desde hacía muchos años era una fuerte aliada de la tisiología para el diagnóstico de las enfermedades pulmonares, entre ellas la TB. Entre estas técnicas se usaron con mucho éxito la fluoroscopia, que era una prueba dinámica que permitía observar las lesiones y los movimientos del pulmón y del resto de los órganos de la caja torácica; la radiografía de $14 \times 17$, conocida normalmente como "Rayos $X$ de tórax", muy difundida, pero a la vez muy costosa, a esto se sumó desde fines de la década de 1950 la FR.

La FR es una fotografía de la imagen fluorescente del tórax, de bajo costo, sencillez y rapidez, y se podían examinar hasta 120 personas/h con los equipos disponibles en aquel momento.

La estrategia de tamización concibió dos modalidades: el uso de equipos fijos, instalados en los Centros de Pesquisa FR y equipos móviles instalados en un vehículo con una planta eléctrica auxiliar.

Los centros de pesquisa se ubicaron en ciudades de más de 100000 habitantes, como el equipo estaba preparado para realizar 120 investigaciones/h, trabajando ocho h diarias, se calculó que podía hacer 960 investigaciones diarias. Estos centros debían estar instalados en el mismo edificio de los dispensarios antituberculosos.

El objetivo era examinar a toda la población laboral de la localidad donde estaban instalados, además, una vez al año, a los convivientes de los pacientes de tuberculosis. Se debían examinar al menos 50000 casos anuales en cada centro y no mas de $150000 .{ }^{12}$ 
En la organización de este trabajo, su puesta en marcha y posterior interpretación y evaluación de los resultados estuvo con magistral actitud y desempeño el doctor Arnaldo Coro del Pozo miembro del Departamento de Tuberculosis.

Las unidades móviles se concibieron con una función principal de trasladarse a los centros laborales donde trabajaban más de 100 personas, ya fueran urbanos o rurales. Ello permitiría hacer investigaciones en masa a la población adulta general. Además, apoyarían a los centros de pesquisa si sus equipos fijos sufrieren algún desperfecto.

En 1961, el doctor Arnaldo Coro del Pozo sugirió un plan de pesquisa para lograr el examen del $30 \%$ de la población adulta de Cuba, en el que preveía que con 12 unidades móviles trabajando y dos de reserva (total de 14 unidades móviles), era posible examinar a la población adulta total de Cuba en tres años.

La planificación propuesta fue la siguiente:

Pinar Río: 87000 personas en 11 meses. La Habana: 357000 en 11 meses ( 3 unidades). Matanzas. 68000 en 8 meses. Las Villas: 179000 en 11 meses ( 2 unidades). Camagüey: 101800 en 11 meses. Oriente Norte: 117600 en 10 meses ( 2 unidades). Oriente Sur: 15300 en 11 meses ( 2 unidades). ${ }^{12}$

La FR masiva fue una estrategia que se llevó a cabo en el país durante la década de nuestro estudio de manera exitosa, además a ella se debe el diagnóstico temprano y el tratamiento oportuno de un grupo importante de personas supuestamente sanas.

\section{Reorganización de los dispensarios antituberculosos}

Los dispensarios antituberculosos (DA) existían en el país desde los inicios del siglo xx, pero en esta década, el doctor Aldereguía Lima y sus colaboradores decidieron darle una nueva dirección a su gestión. La idea era que los DA brindasen una asistencia médica lo más próximo posible al tratamiento hospitalario o sanatorial y por lo tanto este tipo de unidades asistenciales pudieran sustituir al mayor número de camas posibles, para usar estas para los casos más avanzados o que requirieran tratamientos prolongados o quirúrgicos.

Entre las funciones que entonces se le planteaban a los DA, estaban: diagnóstico, clasificación, tratamiento, examen de convivientes, quimioprofilaxis, inicio y vigilancia de los expedientes de subsidio, centros de pesquisa fotorradiográficas (examen que era utilizado como un elemento decisivo para otorgar el certificado de prevención de enfermedades), atención a niños tuberculosos mayores de 3 años, control de todos los tuberculosos de la zona y docencia. ${ }^{9}$

\section{El Primer Forum Nacional de Higiene y Epidemiología}

Este era el panorama que existía a los inicios de la década de 1960 en relación con el conocimiento de la situación que tenía en el país la enfermedad tuberculosa y era el espíritu con que se enfrentaron los especialistas del Departamento de Tuberculosis y la Dirección Nacional de Epidemiología (DNE) del MINSAP. Entre 1959 y 1961 hicieron tal vez más que todo lo hecho entre 1902-1958 por el control de la enfermedad y mejorar la calidad de vida del enfermo de TB y su familia. Ya existían las condiciones objetivas y subjetivas propicias para iniciar un programa de control de la enfermedad. En 1962 se celebró el Primer Forum Nacional de Higiene y Epidemiología, en la Ciudad de La Habana, reunión medular y de capital 
importancia para el abordaje de la prevención y control de enfermedades infectocontagiosas en el país, discutir avances científicos, políticas y estrategias de control. En el seno de esta reunión se plantearon y sometieron a discusión las Bases para el Programa Nacional de Control de la Tuberculosis, donde se contempló ante todo la "prevención, preparación y disposición" que se debía hacer anticipadamente, para evitar el riesgo dado que en la tuberculosis, el período prepatogénico puede dividirse en infección y enfermedad, ya que al implantarse la micobacteria tuberculosa en el hombre sano, en la mayoría de los casos, tendremos como demostración ostensible de esta implantación la prueba de tuberculina positiva, y así la infección puede mantenerse indefinidamente en esta forma. Se reconoció que la mayoría de los casos de reinfección ocurren años después de la primoinfección. ${ }^{13}$

La prevención de la tuberculosis, según este proyecto de base para el programa se debía clasificar en: a) Prevención de la infección, b) Prevención de la enfermedad y c) Prevención de la progresión de la enfermedad.

La prevención de la infección corresponde a la prevención primaria. La prevención de la enfermedad se realiza en el período patogénico, actuando sobre la infección tuberculosa y considerando que esta evoluciona hacia la enfermedad tuberculosa.

La prevención de la progresión puede realizarse en la fase inicial o fase más avanzada y también como medio de evitar las recaídas. ${ }^{13}$

Las medidas de control las dividía en: a) Generales y b) Específicas.

Las medidas generales más importantes serían: 1. Educación, 2. Participación organizada de las masas, 3. Protección económica al tratamiento, 4. Promoción de la salud y 5 . Notificación.

Y las específicas: 1. Conocimiento de la extensión y de las características epidemiológicas de la TB, 2. Profilaxis del foco, 3. Vacunación con BCG, 4. Quimioprofilaxis, 5. Pesquisa FR, 6. Tratamiento: quimioterapia precoz, médico, quirúrgico y profiláctico, 7. Rehabilitación y 8 . Seguimiento (vigilancia y exámenes médicos periódicos).

En este Forum después de los detalles generales se planteó un Programa para el control de la tuberculosis. Consistía en el esfuerzo organizado de la comunidad con el objeto de reducir en los individuos sanos el riesgo de contraer la enfermedad, utilizando las medidas específicas de control más prácticas, aplicándolas en gran escala, es decir, de manera masiva, para activamente interrumpir o retardar el progreso de la historia natural de la TB en aquellos niveles en que puedan esperarse los mejores efectos a un costo aceptable. ${ }^{13}$

Los requisitos necesarios para su aplicación eran: a) Como objetivo la protección a las personas sanas y no únicamente atención a los enfermos, b) Las medidas estaban primero dirigidas a la prevención de la transmisión del agente infectante, incluir también medidas para la disminución del riesgo de que la infección se desarrolle en enfermedad como: vacunación y quimioprofilaxis y c) Los métodos y técnicas usados en el programa debían ser sencillos, efectivos, aplicables masivamente a un costo razonable y con el personal que la comunidad podía proporcionar en ese momento.

Reconocía asimismo que en los últimos años había sido posible el diseño de estos programas de control debido a: 1 . El descubrimiento de medicamentos tuberculostáticos altamente efectivos. 2. El desarrollo de métodos sencillos para la 
FR del tórax. 3. Las mejoras logradas en los métodos y en los productos empleados en la vacunación contra la TB.

Los principios básicos del programa se corresponden con: a) La TB es una enfermedad transmisible y el bacilo tuberculoso su agente infectante. b) El control de la TB es un problema epidemiológico con algunos aspectos clínicos. c) El planteamiento y evaluación del programa y las recomendaciones y decisiones por los métodos y técnicas científicas empleadas, debía basarse en los datos obtenidos correctamente. ${ }^{13}$

El objetivo del Programa era por tanto: eliminar la TB como un problema de salud pública y la reducción sistemática de la prevalencia y de la incidencia de la infección y de la enfermedad tuberculosa en una comunidad. Y planteó como los principales elementos del programa: a. Realizar una Encuesta de prevalencia. b. El estudio de las características epidemiológicas. c. Examen de grandes grupos de personas, aparentemente saludables. d. Tratamiento domiciliario de todos los casos definidos y de los potenciales de TB. e. Vacunación con BCG. f. El personal no profesional podría ser empleado bajo supervisión. ${ }^{13}$

Las necesidades básicas del programa que se contemplaron fueron: 1 . Necesidad de información sobre la extensión y naturaleza del problema de la enfermedad. 2. Conocimiento de los métodos y técnicas que fueran los más eficaces desde el punto de vista técnico y administrativo. 3. El personal necesario para su funcionamiento. 4. Los edificios, equipos, material y otros. 5. La evaluación periódica del programa mediante investigaciones epidemiológicas periódicas y controladas. 6. Que tuviera una dirección y supervisión central.

Las medidas de control que se contemplaron en este primer programa fueron: 1. Encuesta de prevalencia. 2. Vacunación con BCG en masa. 3. Quimioprofilaxis. 4. Pesquisa FR en masa. 5. Tratamiento curativo y profiláctico con los medicamentos tuberculostáticos. ${ }^{13}$

Este Forum de Higiene y Epidemiología fue de trascendental importancia para el desarrollo de la especialidad, además de que constituyó un evento teórico sin precedentes, ya que en el país la especialidad no estaba formalmente constituida. Aunque ya había médicos dedicados a estas funciones en todos los municipios, eran médicos generales o clínicos a quienes les faltaba cierto bagaje teórico propio de esta ciencia, que empezó a desarrollarse en esta época. Esta reunión ayudó a impulsar la capacidad resolutiva de esta masa crítica de profesionales de la salud. En el plano de la TB, sirvió para dar a conocer y someter a discusión el diseño de su primer Programa de Control que se inició al año siguiente.

\section{El primer programa nacional de lucha antituberculosa: 1963}

Entre los antecedentes y justificación de este programa se planteó la elevada mortalidad de la tuberculosis. En 1959 ocupó el 8vo. lugar entre las causas de muerte con 1146 defunciones, 2,6\% de la mortalidad total del país, 17,2 por 100000 habitantes. En 1960, 1054 muertes, 5,0 por 100000 habitantes. ${ }^{15}$ En 1961, la prevalencia en mayores de 15 años era en zona urbana $1,0 \%$ y zona rural 0,5\% (tabla 7). 
Tabla 7. Casos de tuberculosis de todas las formas, aก̃os 1959-1961

\begin{tabular}{|c|c|c|c|}
\hline \multirow{2n|}{*}{ Años } & Población & No. casos & $\begin{array}{c}\text { Tasa incidencia } \\
\text { por } 100000 \text { hab. }\end{array}$ \\
\hline 1959 & 6669046 & 1849 & 27,7 \\
\hline 1960 & 6809526 & 1856 & 27,3 \\
\hline 1961 & 6914123 & 2625 & 38,0 \\
\hline
\end{tabular}

Fuente: tabla confeccionada por Dr. Pascual Gispert.

ob cit.8.

El propósito del programa era la eliminación de la tuberculosis como problema de salud pública en Cuba. Esto significaba la reducción sistemática de la prevalencia y la incidencia de la infección y la enfermedad tuberculosa en una comunidad hasta llegar a alcanzar un nivel que haga innecesaria las organizaciones especializadas en el control de la enfermedad. La OMS consideraba que cuando en una comunidad el $1 \%$ o menos de los niños entre 1-14 años de edad son reactores a la tuberculina, entonces el riesgo de esta comunidad es tan pequeño que no constituye un problema de salud pública. Este era una de las metas que el programa se propuso lograr a mediano plazo.

El programa incluyó los aspectos que se habían presentado en el Forum antes señalado. Se introdujo el concepto de lo que consideró como caso potencial: toda persona en quién el bacilo tuberculoso no ha sido comprobado, pero que muestra ciertas alteraciones en sus pulmones visibles por FR. Estas lesiones pulmonares tienen tendencia a evolucionar hacia la TB definida, con eliminación de bacilos.

Planteó también el uso de la vacunación BCG aplicada en amplia escala, consideró además el empleo masivo de personal no profesional, como las brigadistas sanitarias, para poder lograr la realización de sus actividades. Las medidas de control fueron las mismas que ya se habían enunciado el año anterior: encuestas de prevalencia, vacunación BCG masiva, quimioprofilaxis cuando fuera requerida, la pesquisa FR masiva, el tratamiento curativo de los casos y profiláctico a los convivientes con medicamentos tuberculostáticos.

Para los lugares donde la prevalencia de la enfermedad era alta, planteaba una estrategia especial: la búsqueda activa de la TB por pesquisa FR en masa y la búsqueda de individuos (principalmente niños) anérgicos e hiperégicos mediante pesquisa tuberculínica masiva, hasta una edad determinada. ${ }^{14}$

En esta primera versión de 1963 se incluían objetivos de trabajo para 1964, los cuales eran: 1. Realizar no menos de 500000 FR. 2. Revacunar al $90 \%$ de los niños nacidos en instituciones asistenciales, aproximadamente 157500 recién nacidos. 3. Primovacunar no menos del $30 \%$ de los niños nacidos en sus hogares (aproximadamente 20 500). 4. Dotar a cada Dirección Regional de Salud Pública de un Dispensario Regional de TB. 5. Unificar los procedimientos de notificación, diagnóstico, terapéutica, microbiológicos y de rehabilitación en todo el país. 6 . Lograr la vacunación BCG de los niños de primero a sexto grado de la enseñanza primaria al final del presente año, previa prueba de tuberculina al $40 \%$ de ellos (180 880). 7. Limitación en tiempo y espacio. El programa se realizaría en todo el

http://scielo.sld.cu 
país y en forma permanente hasta alcanzar el propósito fijado. Comenzaría a partir del 15 de abril de $1964 .{ }^{14}$

Este programa consignaba que la Comisión Nacional de Tuberculosis (CNT) tendría como funciones normar, dirigir y supervisar las acciones programadas. El

Departamento de Tuberculosis, sería el responsable del asesoramiento técnico en lo referente a prevención, diagnóstico, tratamiento y rehabilitación de la enfermedad.

Normaba el trabajo del Dispensario Regional de Tuberculosis (DRT), cuya principal función sería realizar investigaciones especializadas a los casos de esta enfermedad remitidos por los otros dispensarios de la región. El Dispensario Antituberculoso Distrital (DATD), sus futuras funciones incluirían: examen y diagnóstico de los casos asintomáticos, examen de los convivientes y control de focos, los tratamientos domiciliarios y ambulatorios. Los Policlínicos Generales: realizarían el examen de los convivientes cuando la distancia a que se encuentra el DATD dificultara su tratamiento en dicho dispensario. Todas estas unidades utilizarían las actividades educativas con el enfermo, su familia y la colectividad.

Para la realización del examen de las grandes colectividades supuestamente sanas, se planteaba el uso de la pesquisa FR, que posibilitaría descubrir los casos definidos y los potenciales. Estos exámenes serían acometidos una parte por los centros fijos que estaban instalados en los DATD y Centros de Prevención de Enfermedades Transmisibles (CPET] y por las Unidades Móviles, dependientes del Departamento Regional. En cada capital de región se instalaría por lo menos un equipo fijo para dar respuesta al servicio de la expedición de los CPET.

Cada regional recibiría uno o más equipos móviles de $\mathrm{FR}$, que ayudarían a examinar el mayor número de supuestos sanos en el menor período posible. Se plantea que lo ideal es al $100 \%$ de la población adulta y preferiblemente a todo mayor de 30 años. Cada centro fijo debería realizar 20000 FR al año y cada unidad móvil 60000. Estas son metas que fueron un objetivo en 1964, lo que con los equipos disponibles podían ser más de 500000 en ese momento. ${ }^{14}$

Se concibió la realización de FR a las personas de 15 años en adelante y a los becados internados aunque fueren menores.

La central del servicio de FR se dispuso como una sección del Dispensario Regional de Tuberculosis y de ser posible en el mismo edificio. En relación a los DATD, el programa dispuso mantener los ya existentes, que debía ser uno en cada distrito, que organizarían y mantendrían actualizados el Registro de los pacientes tuberculosos de sus respectivos distritos: propuso su reorganización y quedaban como sus funciones más importantes: el examen y diagnóstico de los casos sintomáticos, examen de convivientes y control de focos, tratamiento domiciliario y ambulatorio. ${ }^{14}$

Para los Sanatorios propuso mantener los ya existentes, regular los ingresos para que pudieran ser atendidos el mayor número posible de casos recuperados, recomendó aumentar sus camas a 300 para Las Villas y 275 para Oriente Norte. ${ }^{15}$ En los Hospitales de Crónicos se crearían centros de rehabilitación para enfermos irreversibles, ya que en aquel momento había más de 1400 de estos enfermos contagiosos que ocupaban camas en los sanatorios.

Este programa incluyó algo muy avanzado para el momento y de trascendental importancia para el enfermo y su familia: la protección económica al paciente de tuberculosis y su familia. Un paso de avance fue la Ley de Seguridad Social (general), pero esta no resolvía totalmente el grave problema de la protección 
económica al enfermo de tuberculosis y la familia. Aquí se planteó que se debía garantizar el salario completo a estos enfermos durante todo el tiempo que su enfermedad estuviera activa y así se aprobó.

El programa estableció como obligatorio la notificación de los casos de tuberculosis lo que se exigiría a los médicos con estricto cumplimiento, ya que es una Enfermedad de Declaración Obligatoria (EDO) según la Ley de Salud Pública No. 959, de Agosto $1^{\circ}$ de 1961 que quedó establecido en 1962, cuando el Primer Forum de Higiene y Epidemiología. En 1964 cuando se inició este programa de Lucha Antituberculosa se integraron estas actividades en los servicios generales de salud.

En 1965 existían en el territorio nacional nueve Hospitales Antituberculosos con 4080 camas y 42 equipos de FR (29 fijos y 13 móviles). En 1967 había 27 DATD y 9 consultas de tisiología, distribuidas en todo el país. ${ }^{15}$

El pesquisaje de los casos en esa época funcionaba de la siguiente forma: las personas que visitaban los policlínicos generales o integrales y los que se pesquisaban mediante el CPET como sospechosos de TB pulmonar, eran remitidos al DATD, donde se confirmaban o no el diagnóstico. Comprobado el caso, se confeccionaba la tarjeta de EDO, que se remitía a la dirección regional de salud. A pesar de ello en 1967 todavía no existían registros confiables de la prevalencia de la enfermedad. ${ }^{16}$ El aumento de la pesquisa FR determinó un incremento de los casos de TB detectados (tabla 8).

Tabla 8. Fotorradiografias (FR) realizadas y porcentaje de positividad. Cuba, $1959-1965$

\begin{tabular}{|l|c|c|}
\hline Años & No. de FR & \% de TB \\
\hline 1959 & 180463 & 1,0 \\
\hline 1960 & 274785 & 0,8 \\
\hline 961 & 199146 & 0,5 \\
\hline 1962 & 170508 & 0,7 \\
\hline 1963 & 200021 & 0,7 \\
\hline 1964 & 548695 & 0,6 \\
\hline 1965 & 1032351 & 0,4 \\
\hline
\end{tabular}

Fuente: Departamento de Estadísticas del MINSAP.

Sin embargo, esta labor disminuyó su rendimiento por haber sido un tanto indiscriminada y repetida a los mismos grupos de población y edades. De todos modos el aumento de la pesquisa determinó un incremento de la incidencia, de 52,6 en 1964 a 65,0 en 1965, para descender a 36,5 en 1966. La disminución en este último año pudo deberse al bajo número de FR realizadas y sin priorizar a los grupos de riesgo. ${ }^{15}$ Las tasas más altas por provincias en 1964 fueron Matanzas y Camagüey con 79,0 y 76,1 por 100000 habitantes (tabla 9). En 1965 fueron sobrepasadas por Oriente Sur con 100,6. La prevalencia en 1965 era de 0,3\%. 
Tabla 9. Casos notificados de tuberculosis por provincias. Cuba, 1964-1966

\begin{tabular}{|l|c|c|c|c|c|c|}
\hline \multirow{2}{*}{ Provincias } & \multicolumn{2}{|c|}{1964} & \multicolumn{2}{|c|}{1965} & \multicolumn{2}{|c|}{1966} \\
\cline { 2 - 4 } & Casos & Tasa & Casos & Tasa & Casos & Tasa \\
\hline P. del Ría & 297 & 53,3 & 343 & 59,9 & 242 & 41,1 \\
\hline La Habana & 1402 & 69,3 & 1070 & 52,0 & 377 & 18,1 \\
\hline Matanzas & 353 & 79,0 & 279 & 61,1 & 121 & 26,1 \\
\hline Las Villas & 515 & 43,7 & 656 & 54,2 & 496 & 40,1 \\
\hline Camagüey & 598 & 76,1 & 661 & 81,8 & 473 & 57,2 \\
\hline Oriente Norte & 312 & 32,6 & 345 & 37,0 & 304 & 31,8 \\
\hline Oriente Sur & 432 & 29,1 & 1604 & 100,6 & 833 & 50,7 \\
\hline
\end{tabular}

Fuente: Departamento de Estadisticas del MINSAP.

La evolución de la incidencia y la mortalidad se aprecia en la tabla 10.

Tabla 10. Tasa de incidencia y mortalidad por Tuberculosis. Cuba, 1954-1966

\begin{tabular}{|c|c|c||c|c|}
\hline Años & \multicolumn{2}{|c|}{ Casos } & \multicolumn{2}{c|}{ Defunciones } \\
\cline { 2 - 3 } & No. & Tasa & No. & Tasa \\
\hline 1954 & 2118 & 35,3 & 1312 & 21,9 \\
\hline 1955 & 1749 & 28,5 & 1160 & 18,9 \\
\hline 1956 & 1951 & 31,2 & 1158 & 18,5 \\
\hline 1957 & 1838 & 28,8 & 1175 & 18,4 \\
\hline 1958 & 1562 & 24,0 & 1076 & 16,5 \\
\hline 1959 & 1849 & 27,7 & 1146 & 17,2 \\
\hline 1960 & 1856 & 27,3 & 1050 & 15,4 \\
\hline 1961 & 2625 & 38,0 & 1204 & 17,4 \\
\hline 1962 & 2818 & 40,1 & 1402 & 20,0 \\
\hline 1963 & 2768 & 38,8 & 1405 & 19,7 \\
\hline 1964 & 3909 & 52,9 & 1159 & 16,0 \\
\hline
\end{tabular}




\begin{tabular}{|l|l|l|l|l|}
\hline 1965 & 4958 & 65,0 & 1052 & 13,8 \\
\hline 1966 & 2846 & 36,5 & 996 & 12,8 \\
\hline
\end{tabular}

Fuente: Departamento de Estadísticas del MINSAP. Tasas por 100 000hab.

En 1967, se hizo un análisis del desarrollo del programa y se le agregaron nuevos aspectos, que fueron: 1 . Integración (parcial) del Programa de Control a los servicios generales de salud. 2. Desarrollo de la microbiología de la tuberculosis en la periferia. 3. Consolidación de la protección infantil de las áreas rurales mediante la vacunación BCG directa en campaña masiva. 4. Reorganización de los Registros de TB. 5. Mejor utilización y aprovechamiento de los recursos disponibles. 6. Mejorar e intensificar la formación de todo el personal de salud pública con un criterio integral con énfasis en la enseñanza de los aspectos de la tuberculosis. ${ }^{15}$

Una revisión de los aspectos técnicos del control de la tuberculosis en esa época, ${ }^{16}$ revela que la enfermedad continuaba como el principal problema de salud del país y esta situación solo cambiaría cuando menos del $1 \%$ de los niños menores de 14 años de edad, tuviesen una reacción específica a la dosis estándar de Tuberculina. Para logarlo era indispensable la integración del programa de control a los Servicios Generales de Salud Pública, poniendo en manos del Policlínico Integral, del Médico general y las Enfermeras de Terreno, las medidas de control, como se planteó en los ajustes hechos al programa.

La lucha contra la enfermedad se orientó entonces hacia: I. Protección de los susceptibles. II. Eliminación del reservorio humano y animal. III. Búsqueda de las fuentes de contagio desconocidas, para su eliminación.

Para proteger a los susceptibles se planteó la vacunación BCG, con prueba de Tuberculina previa, para separar a la población en infectados y no infectados y proceder a la vacunación de estos últimos. Se utilizó entonces un BCG de cepa Moreau, fabricado en los laboratorios del Instituto Nacional de Higiene, Epidemiología y Microbiología (INHEM). También el uso de quimioprofilaxis con Isoniacida ( $5 \mathrm{mg} / \mathrm{kg}$ de peso) a niños menores de 3 años que eran contactos de pacientes positivos, que resultaron reactores a la tuberculina y a todo menor de 15 años, cuya prueba de Mantoux resultara de $15 \mathrm{~mm}$ o más. En un intento de interactuar sobre las vías de transmisión tratarían de mejorar las condiciones socioambientales, especialmente en el aspecto sanitario dentro de la vivienda. Y sobre el reservorio se planteó en esos momentos el tratamiento y control de los enfermos, la pesquisa FR en los presuntos sanos, la quimioprofilaxis y la eliminación del reservorio animal. ${ }^{16}$

Se dispuso también el aislamiento hospitalario en los primeros estadios de la enfermedad hasta lograr la conversión (negativización) del esputo. Para ello se disponía de 3545 camas distribuidas en nueve hospitales en todo el país, que se había decidido ampliar antes hasta algo más de 4000 camas. Se reconocía ya en este momento el gran valor del examen directo de esputo. Todos los policlínicos tenían ya microscopios y reactivos, que podían ser utilizados para cumplir con esta etapa del diagnóstico. ${ }^{17-19}$

Los indicadores epidemiológicos más importantes que se usaban para evaluar la magnitud del problema de la TB y la marcha del programa eran: 1 . Prevalencia e incidencia de la infección. 2. Prevalencia e incidencia de excretores de bacilos al examen directo de esputo. 3. Prevalencia e incidencia de enfermedad activa 
demostrada bacteriológicamente. 4. Recaídas y prevalencia de cepas de TB resistentes a los medicamentos. 5. Proporción de resistencia primaria. 6 . Análisis de la mortalidad y morbilidad según extensión de las lesiones. 7. Índices de evaluación del tratamiento hospitalario. ${ }^{16}$

También se propuso trabajar entre los grupos de riesgos de la enfermedad, que se reconocieron como: Contactos de TB activa bacilífera, a) Personas con síntomas respiratorios que consultan en policlínicos y hospitales. b) Personas con lesiones fibrosas antiguas en pulmones. c) Personas que trabajan en hospitales y unidades de la lucha anti tuberculosa. d) Hombres adultos mayores de 45 años de edad. e) Mujeres mayores de 65 años. f) Obreros expuestos al polvo de sílice. g) Obreros de granjas y mataderos de ganado tuberculoso. h) Diabéticos y alcohólicos crónicos. i) Mujeres después del sexto mes de embarazo. j) Personas que trabajan con niños. k) Manipuladores de alimentos.

Aunque en la práctica la pesquisa se dirigió a: a) Contactos y convivientes. b) Personas consultantes a policlínicos generales y hospitales. c) Personas con sintomatología respiratoria. d) Adultos mayores de 45 años. e) Otros grupos especiales.

El problema de la TB en la infancia había sido una situación grave por su magnitud antes del triunfo de la revolución y que se mantuvo en los primeros años de la década del 1960. A la lucha contra este flagelo se le prestó especial importancia. ${ }^{20}$ Los preventorios fueron desactivados en los primeros años de la década. En noviembre de 1966, se inauguró el Servicio de Tisiopediatría del DATD "Dr. Eduardo Angles", del Regional Marianao. Durante 1967 fueron examinados en este dispensario 1537 niños, consistiendo el examen en exploración a través del interrogatorio y examen físico, la intradermorreacción (Mantoux), con tuberculina y el examen radiológico del tórax, examen microbiológico y biopsias en los casos indicados. Más de la mitad de los niños diagnosticados con la enfermedad tenían contactos con enfermos tuberculosos adultos y de los hiperérgicos el $39 \%$ eran contactos de pacientes tuberculosos. ${ }^{20}$

La vacunación BCG de la población infantil se extendió a todos los rincones y en los centros urbanos alcanzó más del $90 \%$ de los nacidos vivos. El tratamiento de la enfermedad a escala nacional se realizaba por medio de los servicios hospitalarios de pediatría en enfermedades respiratorias (antes tisiopediatria) como Centro Nacional de Referencia al servicio de TB y otras enfermedades respiratorias del Hospital Pediátrico Universitario "Ángel A. Aballi", al frente del cual estaba el profesor doctor José Mir del Junco, auxiliado por el profesor doctor Eduardo Marina.

Lo más significativo de la integración del control de la tuberculosis en ese período fue la participación de los Policlínicos Integrales en esta actividad mediante las visitas domiciliarias del personal de terreno, el examen y control de los convivientes y la campaña de vacunación BCG en los escolares. ${ }^{20}$

\section{Investigaciones bacteriológicas en TB}

Desde 1966, el desarrollo de una red de laboratorios de microbiología, donde se podía realizar el diagnóstico bacteriológico de la tuberculosis, con el adiestramiento del personal para este trabajo, fue una fortaleza que se sumó al programa y el incremento de las acciones de control de contactos junto a la vacunación BCG. Marcó una etapa que permitió un estudio más profundo de la situación de la enfermedad. Con el inicio de la aplicación de las medidas de control epidemiológicas derivadas de la bacteriología, dio un vuelco a la clasificación de los enfermos en el registro de los DATD, reorganizándolos en casos considerados "activos" para el 
informe de la prevalencia y dentro de estos se separó el grupo que tenía bacteriología positiva llamándolos Grupo dispensarial I (Activos bacilíferos).

En 1969 después de la aplicación de nuevos criterios para la clasificación y recolección de datos, se contabilizó 2753 enfermos activos, para una tasa de prevalencia de TB activa bacilífera de 50,7 por $100000 .{ }^{10}$ En la década que estudiamos la mortalidad disminuyó de 19,8 a 10,7 por 100000 desde 1962 a 1969.

\section{Residencia de neumotisiología}

Con el impulso y apoyo permanente de los Profesores Gustavo Aldereguía Lima y Francisco Pérez Carballos (Director Nacional de Docencia de Posgrado del MINSAP) se aprobó la creación de la Residencia de Neumotisiología como una especialidad priorizada al final del año 1967 y comenzó en febrero de 1968. La elaboración del programa estuvo bajo la dirección del profesor doctor Rafael O. Pedraza Rodríguez con la participación de los doctores José Mir del Junco, Alberto Hernández Cañero, Gustavo Aldereguia Lima, Ricardo Sánchez Acosta, Eduardo Pentón Dustad, José A. Valdivia González y Edilberto González Ochoa. El primer grupo matriculado y graduado estuvo integrado por los doctores: Luisa Armas Pérez, Libertad Carreras Corzo, Pastor García, Mario Hernández, Rodolfo Rodríguez Cruz, Coralia Torres Fernández, Sánchez Delgado y Mariana Silverio. Este grupo realizó un primer año presencial en diversos servicios de La Habana, un segundo año trabajando en las provincias y un tercero en provincia Habana para culminar sus tesis de terminación de residencia (especialización).

\section{Luchadores contra la TB 1959-1969}

Desde 1959 hasta el final de la década de los años 60, trabajaron en la lucha contra la TB, la planificación y aplicación del primer programa de control, su desarrollo y evaluación, los especialistas del Departamento de Tuberculosis y la Comisión Nacional de Tuberculosis: el doctor Gustavo Aldereguía Lima, jefe del Departamento, fue el motor impulsor de toda esta lucha y del desarrollo y aplicación del programa; el doctor Arnaldo Coro del Pozo, responsable de la pesquisa FR, Luis Pascual Gispert y Agustín Lage Saceiro, de la parte clínica y la Licenciada Dalia Fernández Vila tuvo a su cargo la formación y actualización del conjunto de enfermeras auxiliares de la lucha antituberculosa (ALA) y del seguimientos, supervisión, asesoría y control de su trabajo. La Comisión cesó sus funciones en el año 1966 y el Departamento pasó desde el Viceministerio de Asistencia Médica al de Higiene y Epidemiología por la Resolución Ministerial No. 30/08. Poco tiempo después se creó el Grupo Especial de Tuberculosis del nivel nacional del MINSAP, integrado por el Profesor Gustavo Aldereguía Lima (jefe del grupo), Dalia Fernández Vila, Edy Frías Méndez, Edilberto González Ochoa (secretario), José Mir del Junco, Eduardo Marinas, José Hernández Navarro, Rafael Pedraza Rodríguez, José A. Valdivia y Roberto Suárez Méndez. Participaban en las sesiones del Grupo Especial de Tuberculosis y eran los coordinadores responsables provinciales del PNCT los siguientes especialistas: José Alfonso Cañal (Pinar del Rio), Ramiro Estévez (La Habana), René Muñiz (Matanzas), Rafael Morales (Las Villas), Víctor Romero Sóñora (Camaguey), José Sevy Court (Oriente Norte). Además dirigieron los DATD, entre otros, los doctores Manuel Trujillo Mero, Manuel Durán, Manuel Álvarez Guin, Agustín Ruiz Landa, Ernesto Calzado, Adrian García, Flavio Lima, Israel González Menocal, Enrique Vicent, Miguel Benavides, Ana María del Castillo, José Valliny. Trabajaron principalmente en los Sanatorios y Hospitales Antituberculosos, entre otros, Andrés Flores, Ricardo Sánchez Acosta, Eduardo 
Pentón Dusted, José Suárez Madrado, Francisco Berbes Carrillo, Manuel Trujillo, Luis Muñoz Godoy, Dalia Carbonell, José Almiral, Juan Antonio Oviedo, Armando Alonso Frade, Serbio Carol del Valle, Julio Rodríguez Quintero, Miguel Bueno, Rafael Meneses María, José Arrazuria, Enrique Barreras Miranda, Joaquín Obregón Pereira, Raúl del Pago, Raúl García Díaz, José Palteron, Inés Gary, Armando Bestard, Ángel Rigual, Mirabal, Silvia Jústiz, Carlos Vincent, José Duarte, José Estrada, José Palmero Dupuy, Rabel Valdés y Jorge Castellanos.

Merecen una mención muy especial los microbiólogos que montaron las técnicas y desarrollaron todo lo relacionado con el diagnóstico bacteriológico de la tuberculosis con el recientemente fallecido profesor José A. Valdivia al frente del mismo. En estos laboratorios de bacteriología trabajaron entre otros Julián Pérez Amarillo, Aida Jaime Menéndez Cañizares, Caridad Pérez Ferrá, Roberto Suárez Méndez, Zalazar Fajardo, Carlos Suárez Méndez, Elba Olivares Sánchez.

Muy importante resultó el trabajo de las técnicos, Aida Arnet, Silvia Dumas y Miguel Echemendía.

Fueron asesores extranjeros en esta lucha los doctores Manuel Zúñiga, (chileno); Franklisek Kriegel (checo) y Egon Werner y Roy Neubert (República Democrática Alemana). Considero que fueron asesores trascendentes para la lucha contra la TB en este período.

\section{Aspectos importantes en el control de la enfermedad}

El panorama que presenta el control de la tuberculosis en Cuba durante la década de 19591969, estuvo marcado por los siguientes aspectos:

- Se abandona la vacunación oral con BCG y se inicia su aplicación intradérmica al nacimiento y revacunación a la entrada escolar.

- Se introduce el tratamiento ambulatorio, que conlleva la reinserción social del enfermo, lo que rompe el aislamiento y comienza a remover el estigma social que conlleva esta enfermedad. Este tipo de tratamiento es un paso importante y científicamente respaldado ante la posibilidad de la eliminación de la enfermedad en el futuro, como el objetivo principal del programa a largo plazo.

- Se empieza a hablar de la curación, cuando se negativiza el paciente y se mantiene en tratamiento, se considera entonces que ya no es infectante. Esto ocurre después de la introducción del diagnóstico bacteriológico.

- Se comienza a realizar el control de foco y la historia epidemiológica de cada caso nuevo. Se inicia la quimioprofilaxis en los convivientes indicados.

- Se decide mantener el $100 \%$ del salario a los pacientes en tratamiento a partir de 1969. Esta medida es una garantía para el enfermo y su familia al tiempo que favorece la disminución del abandono de los tratamientos.

Se puede concluir que a partir de 1959 se inicia formalmente la lucha antituberculosa en Cuba con una nueva visión y un apoyo oficial como nunca antes ocurrió en el país. Se establece un Departamento Nacional de Tuberculosis dirigido por el doctor Gustavo Aldereguía Lima, más tarde en 1963 se inician los trabajos del Programa Nacional de Control de la Tuberculosis, que unifica y centraliza la

http://scielo.sld.cu 
lucha contra la enfermedad y tiene notables logros en la década 1959-1969. Es de trascendental importancia la introducción del diagnóstico microbiológico.

\section{REFERENCIAS BIBLIOGRÁFICAS}

1. Organización Mundial de la Salud. Plan Mundial para detener la Tuberculosis 2006-2015. Actuar para salvar vidas, Alianza Alto a la TB. Ginebra: OMS; 2006.

2. Organización Panamericana de la Salud. Plan Regional Alto a la Tuberculosis. 2006-2015. Washington, D. C.: OPS; 2006.

3. González E, Armas L. Eliminación de la Tuberculosis como problema de salud pública. Una elección acertada. Rev Esp Salud Pública. 2007;81:59-62.

4. González Ochoa E, Armas L, Llánes MJ. Progress towards tuberculosis elimination in Cuba. Int J Tuberc Lung Dis. 2007;11:405-11.

5. World Health Organization. Global Tuberculosis Control: surveillance, planning, finances. WHO report 2006. Geneva: WHO; 2006.

6. Aldereguía Lima G. La Lucha Antituberculosa en Cuba. Crítica histórica y examen político del problema y endemia. En: Estudios sobre Tuberculosis pulmonar. Orientaciones para la lucha antituberculosa en Cuba. La Habana: MINSAP; 1962. p. 23-64.

7. Aldereguía Lima G. Programa para el control de la tuberculosis. En: Estudios sobre Tuberculosis pulmonar. Orientaciones para la lucha antituberculosa en Cuba. La Habana: MINSAP; 1962. p. 107-82.

8. Pascual Gispert L. Extensión del problema de la Tuberculosis en Cuba. En: Estudios sobre Tuberculosis pulmonar. Orientaciones para la lucha antituberculosa en Cuba. La Habana: MINSAP; 1962. p. 75-106.

9. Argüeyes Casals C. Funciones y nueva organización de los Dispensarios Antituberculosos. En: Estudios sobre Tuberculosis pulmonar. Orientaciones para la lucha antituberculosa en Cuba. La Habana: MINSAP; 1962. p. 256.

10. González Ochoa E. Epidemiología de la Tuberculosis: extensión del problema en Cuba. Bol Hig Epidemiol. 1971;9(1):3-12.

11. Ballesteros R, Hernández Pérez JM. Contribución al estudio de los diversos índices de infección tuberculosa en Cuba, en diversas edades. Rev Cubana Tub. 1952;16:311-23.

12. Coro del Pozo A. Unidades Móviles de Pesquisa Fotorradiográfica. En: Estudios sobre Tuberculosis pulmonar. Orientaciones para la lucha antituberculosa en Cuba. La Habana: MINSAP; 1962. p. 245-52.

13. Menéndez Castañedo M. Organización de los Centros de Pesquisa Fotorradiográfica. En: Estudios sobre Tuberculosis pulmonar. Orientaciones para la lucha antituberculosa en Cuba. La Habana: MINSAP; 1962. p. 237-50.

14. Programa Nacional de Lucha Antituberculosa. La Habana: MINSAP; 1963.

http://scielo.sld.cu 
15. González Ochoa E. Información existente sobre Tuberculosis humana en Cuba. Bol Hig Epidemiol. 1967;5(3):331-3.

16. Breve revisión de los aspectos fundamentales en el control de la Tuberculosis. Bol Hig Epidemiol. 1968;6(3):215 28.

17. Normas Nacionales para el trabajo de Bacteriología de la tuberculosis. Bol Hig Epidemiol. 1964;2:55-73.

18. Normas Nacionales de Microbiología en Tuberculosis. La Habana: Ministerio de Salud Pública; 1965.

19. Valdivia J, González Ochoa E. Situación de la red de laboratorios de tuberculosis en Cuba. Bol Hig Epidemiol. 1967;5(3).

20. Casanova A. Información sobre el control de la tuberculosis infantil en la Región de Marianao, durante el año 1967. Bol Hig Epidemiol. 1968;6(3):239-46.

Recibido: 15 de septiembre de 2011.

Aprobado: 20 de octubre de 2011.

Enrique Beldarraín Chaple. Centro Nacional de Información de Ciencias MédicasInfomed. Calle 27 No. 210, e/ M y N, El Vedado 10400. La Habana, Cuba.

Telefax (537) 832 4402. Correo electrónico: ebch@infomed.sld.cu 